\title{
L'EQUILIBRE AGRO-SYLVO-PASTORAL EN CHAMPAGNE CRAYEUSE
}

A la suite des demandes de défrichement de plus en plus nombreuses, concernant les reboisements résineux de la Champagne crayeuse, l'Administration des Eaux et Forêts s'est émue et a constitué une "Commission de la Champagne », présidée par M. l'Inspecteur Général RIvÉ; cette commission a été chargée d'étudier le problème de la mise en valeur de la Champagne, de la "vocation " des sols de craie et de la réalisation de l'équilibre entre l'agriculture et la forêt dans cette région. Dans cet article, nous nous inspirerons des travaux de cette commission, tout en donnant également notre point de vue personnel.

$$
\text { I . - Le Milieu. }
$$

C'est surtout le sol de la Champagne qui lui donne son originalité ; les sols de craie offrent, en effet, des propriétés très particulières: il s'agit de sols très superficiels, parfois (" squelettiques ), de type " rendzine blanche ) extrêmement riche en carbonate de chaux (60 à $75 \%$ sur la craie blanche sénonienne). Cet excès de calcaire confère au sol une grande pauvreté chimique; les éléments minéraux sont tantôt insolubilisés, donc inassimilables (phosphore - fer); tantôt, au contraire, lessivés, faute d'éléments absorbants pour les retenir (potassium). La matière organique fraîche (humus forestier fumier - compost, etc...) se décompose très rapidement - à condition qu'elle soit bien incorporée au sol minéral - en libérant de l' " azote minéral ) (ammoniacal et nitrique) assimilable par les végétaux, mais pouvant aussi aboutir à des pertes importantes d'azote par lessivage; au cours de cette décomposition, il se forme également un " résidu ), très stable et très résistant à l'action microbienne, l'humus colloïdal, qui ne présente qu'un faible rôle nutritif en lui-même, mais qui, nous le verrons, joue cependant un rôle essentiel dans le maintien de la fertilité.

$\mathrm{Au}$ point de vue physique, les sols de craie passent, à tort, pour être des sols très secs: sans doute est-ce exact pour beaucoup de stations, sur pente, à sols très superficiels, recouverts du ( savart ») ou pelouse à Graminées xérophiles ; mais pour les sols suffisamment profonds, la craie, grâce à sa porosité capillaire très élevée, peut garder, en profondeur, une réserve d'eau suffisante pour permettre aux récoltes de passer le cap difficile des périodes sèches: c'est là un facteur très important, au point de vue agricole. 
Malgré cette restriction, il n'en reste pas moins vrai que la Champagne crayeuse offre, dans son ensemble, un " microclimat du sol ) plutôt sec; cette tendance est accentuée par la sécheresse relative du climat général: la pluviosité ne dépasse guère $600 \mathrm{~mm}$ environ, à Châlons et à Troyes.

C'est à ces conditions physiques particulières que la Champagne doit de n'avoir jamais été, à proprement parler, une région forestière: Si l'on en croit la note de FLICHE (I) et la thèse de LAURENT (2) sur la végétation originelle de la Champagne, il semble qu'il s'agisse d'une (pseudo-steppe ), parsemée de buissons calcicoles. Les seules véritables forêts, d'ailleurs très ouvertes et constituées d'espèces xérophiles (Chêne pubescent), se trouvaient en lisière de la Champagne, sur des terrasses graveleuses à sol relativement profond (les “ Garennes » primitives).

\section{II. - AsPeCts DE L'ANCIENNE ÉCONOMIE RURALE.}

Jusqu'à la guerre de I939-45, un équilibre agro-sylvo-pastoral a bien été réalisé en Champagne, mais il reposait essentiellement sur une mise en valeur ( extensive ) des possibilités de la région. L’agriculture disposait de faibles moyens; seule une petite surface, régulièrement entretenue et engraissée, était cultivée de façon satisfaisante, au voisinage immédiat des fermes. Les parties périphériques des domaines agricoles étaient, soit soumises à une culture très pauvre et extensive, soit transformées en (" terrains de parcours ) à moutons; il fallait une grande surface de ces ( savarts ), caractérisés par des Graminées dures et xérophiles (Festuca duriuscula Bromus erectus), parfois un Genêt (Genista pilosa), pour nourrir un maigre troupeau de moutons. Quant à la " forêt ), elle était loin d'être inexıstante, puisque les reboisements en Pins, datant d'un siècle, représentaient près de $20 \%$ de la surface totale: mais il s'agissait d'une poussière de petits bois de faible étendue, constitués par des peuplements de pins sylvestres extrêmement médiocres et à croissance très lente: les sols calcaires ne paraissent pas, en effet, convenir au Pin sylvestre, qui n'y trouve pas les champignons acidiphiles nécessaires à la constitution de ses mycorhizes; dans ces conditions, la production ne dépasse pas 2 à $3 \mathrm{~m}^{3}$ par hectare et par an (dont $25 \%$ seulement de bois de mine). Dans les meilleurs cas, à vrai dire assez rares, on avait affaire à des pins noirs, à fût plus droit et à croissance plus rapide, donc d'un meilleur rendement économique (4 à $7 \mathrm{~m}^{3}$ par ha et par an, suivant les stations, dont $70 \%$ de bois de mine).

Constatons donc que l'ancienne économie rurale de la région était

(I) Fuiche. La Champagne crayeusé, étude de géographie botanique (Mémoires de la Société académique de l'Aube, LXXII, 1908).

(2) Laurent. La végétation de la Champagne crayeuse. T. I ${ }^{\text {er }}$. Paris, I92I. 
caractérisée essentiellement par le faible rendement des différentes mises en valeur: culture - élevage - forêt. La Champagne apparaissait comme une des régions de France les plus pauvres; mais on pouvait se demander s'il n'existait pas un moyen de tirer meilleur parti, à l'aide de procédés plus modernes, des conditions de milieu existantes, si défavorables soient-elles!

\section{III. - LE PROBLÈME ACTUEL.}

Depuis la dernière guerre, le problème se pose, en Champagne, sous un tout autre jour: un peu partout, il s'installe actuellement de grandes exploitations, dotées de capitaux considérables et de moyens matériels puissants, qui pratiquent une agriculture intensive sur de grandes surfaces. Le sol, bien que pauvre en lui-même, s'avère être un excellent " support ) pour les cultures, à condition qu'il soit suffisamment transformé et enrichi par l'homme. Grâce à la motorisation, un travail du sol intensif devient possible, même sur les terrains les plus éloignés des fermes; il permet d'approfondir les sols superficiels, si on se rappelle que la roche-mère, particulièrement tendre, se laisse très bien entamer par le soc d'une charrue; l'emploi massif d'engrais rend au sol tous les éléments minéraux et azotés qui lui font défaut (et même les éléments qui agissent à l'état de trace, les " oligo-éléments ), comme le bore pour la culture de la betterave). Sur ces sols, initialement si pauvres, on arrive à obtenir des rendements remarquables: plus de 40 tonnes à l'hectare de betterave à sucre; .30 à 35 quintaux de blé à l'hectare.

Par contrecoup, la disparition des mises en valeur les plus extensives, reliques de l'ancienne économie rurale d'avant guerre, tend à se généraliser; les défrichements des mauvais bois de pins sylvestres se multiplient, dans le but d'accroître les surfaces cultivées; au fur et à mesure que les savarts sont eux-mêmes mis en culture, les troupeaux de moutons qui s'y nourrissaient s'amenuisent; en même temps, il ne faut pas l'oublier, une des rares sources de fumure organique, utilisable dans la région, se tarit progressivement.

Ainsi, si on n'y prenait garde, la culture intensive pourrait s'implanter de manière exclusive en Champagne et éliminer toute autre forme de mise en valeur: la forêt et l'élevage! On peut se demander s'il n'en résulterait pas un réel déséquilibre, dommageable à l'avenir économique de la région; en particulier, les spécialistes se posent deux questions essentielles:

a) La fertilité du sol champenois, soumis à un tel mode de culture intensif, se maintiendra-t-elle après les défrichements ? Sans doute, la culture profite, dans les premières années, de l'humus forestier superficiel, qui, une fois enfoui, se décompose très rapidement. Lorsque cette réserve d'humus sera épuisée, la fertilité du sol subsistera-t-elle? 
b) Le déboisement total de la Champagne n'aurait-il pas de conséquence grave, en ce qui concerne ( l'équilibre physique ) de la Champagne? On peut craindre notamment les effets nocifs du vent, tant sur les cultures elles-mêmes que sur le sol.

Nous allons essayer de répondre successivement à ces deux questions.

\section{IV. - Le maintien de LA fertilité des sols DE culture.}

Nous avons dit que le sol champenois était chimiquement pauvre, mais qu'il constituait un bon support physique: encore est-il nécessaire que les propriétés favorables de ce support puissent se maintenir et ne se dégradent pas, sous l'influence d'une culture intensive prolongée!

Or, on constate que les sols de craie ne conservent leur fertilité initiale - également liée aux diverses améliorations d'origine humaine, dont nous avons parlé - qu'à condition que leur taux d'humus reste suffisant: l'humus joue, en effet, un rôle essentiel dans les sols de craic. Résumons brièvement ce rôle de l'humus, qui est triple:

- Il est l'agent de la structure, car il constitue le ciment des agrégats qui caractérisent une bonne structure; celle-ci permet l'aération du sol et, en même temps, le maintien des réserves d'eau indispensables.

- Il assure au sol un pouvoir absorbant suffisant, pouvant retenir les engrais minéraux et empêcher leurs pertes par lessivage, tout en les maintenant disponibles pour les plantes.

- Il améliore la nutrition minérale et azotée, qui se fait mal en présence d'un excès de calcaire, à $\mathrm{pH}$ voisin de 8 ; il décompose, en effet, une partie du calcaire actif et abaisse le $\mathrm{pH}$ aux environs de la neutralité (7), ce qui permet une bien meilleure nutrition des plantes. En un mot, l'humus se comporte en antidote du calcaire en excès. .

Or, après défrichement, la culture, pratiquée sans apport de matière organique, a pour effet d'abaisser dangereusement la teneur du sol en humus: lorsque celle-ci tombe en dessous de $4 \%$. qu'on peut considérer comme un tanx limite, la structure se détruit, les terres deviennent ( battantes ); les pluies ne s'infiltrent plus et les pertes d'eau par évaporation sont considérables, ce qui aboutit à un épuisement des réserves d'eau profondes du sol en saison sèche: la fertilité décroît dangereusement.

Le problème revient donc à maintenir dans le sol un taux d'humus suffisant, seule condition de sa fertilité; or, le cultivateur dispose, à cet effet, de deux moyens, qu'il doit utiliser concurremment : I - l'emploi massif des fumures organiques; 2 - l'intercalation dans l'assolement de prairies temporaires, à base de Légumineuses (Sainfoin, Minette, voire Luzerne sur les meilleurs sols), durant 2 à 3 
ans. Elles se comportent en excellents régénérateurs de la structure, car elles incorporent au sol un humus résiduel, riche en azote, de propriétés très favorables.

Mais on peut se demander où trouver les fumures organiques indispensables, dans un pays où le fumier est rare ? Certes, le « fumier artificiel " (préparé à l'aide de lits de paille périodiquement arrosés par une solution de sulfate d'ammoniaque) peut remplacer avantageusement le fumier naturel, sur les sols de craie, mais il revient très cher; on se trouve donc ramené à un problème d'élevage : l'intensification de la culture en Champagne est étroitement liée à celle de l'élevage.

\section{V. - Le MAINTIEN DE L'ÉQUILIBRe PHYSIQUe DU PAYS}

Si la forêt n'offre, en Champagne, comparativement à la culture, qu'un intérêt économique réduit, il ne faut pas oublier qu'elle est indispensable au maintien de l'équilibre physique du pays. Un déboisement total serait dangereux, d'abord parce qu'il favoriserait une érosion intense du sol, ensuite parce qu'il priverait d'abri, à la fois les surfaces cultivées et les troupeaux.

- L'érosion peut être dangereuse, aussi bien l'érosion pluviale que l'érosion éolienne: La première a tendance à dénuder les croupes, les pentes, de leur sol qui est entrainé vers leş fonds. Déjà, en bien des points, on peut observer la craie $\grave{a} n u$, sur beaucoup de pentes ravinées par les pluies: les cultivateurs ont constaté que, dans ces stations, les rendements étaient particulièrement faibles, en années sèches, faute de réserves d'eau dans le sol; en outre, l'érosion éolienne, si elle n'est pas brisée par des " barrières forestières ), disposées de place en place à l'encontre des vents dominants, risque d'emporter les éléments fins du sol - les plus précieux — argiles, humus, en véritables tourbillons de poussière, comme c'est le cas dans toutes les régions à tendances steppiques. Signalons que PorNsot a insisté dans une publication récente, sur le danger de l'érosion en Champagne sous l'influence du déboisement.

- La protection des cultures et dès troupeaux contre les vents desséchants n'est pas moins indispensable: en saison sèche, il importe de limiter la transpiration des plantes cultivées par tous les moyens, si l'on désire obtenir les rendements maxima; ce problème se posera également pour les troupeaux, de façon d'autant plus aiguë qu'on envisage, précisément, de les reconstituer, comme nous le verrons dans la conclusion.

Il faut donc maintenir une surface minima boisée, qui pourra être beaucoup plus faible que celle actuellement existante, à condi- 
tion qu'elle se présente sous forme de bandes allongées, orientées à l'encontre des vents dominants et bordant les domaines agricoles: de cette façon, un véritable compartimentage de la Champagne pourra être réalisé. On rejoint ainsi curieusement l'antique conception du (" bocage ), mise en pratique depuis des siècles dans l'Ouest de la France et qui a admirablement protégé le sol contre l'érosion, même dans les régions les moins forestières, telles que l'Ouest du Massif Central et la Bretagne.

Mais si le point de vue de la protection du sol et des cultures doit passer au premier plan, il ne faudra pas négliger pour autant le point de vue économique; les bandes boisées devront être assez larges, pour fournir des peuplements rentables, et surtout elles devront être constituées d'essences plus précieuses, mieux adaptées au sol que le Pin sylvestre. Citons par exemple: le Pin noir, à introduire sur les sols nus superficiels; le Pin laricio de Corse, sur les sols nus mais plus profonds; le Sapin de Nordmann, sous le couvert des mauvais peuplements existants, ceux-ci devant être rapidement éliminés par la suite. Le Douglas pourra être essayé dans les meilleurs sols. Enfin, il ne faudra pas négliger l'introduction en mélange, dans un but cultural, de feuillus fixateurs d'azote, destinés à l'amélioration de l'humus (Aune à feuilles en cœur sur les bons' sols, Aune glutineux dans les bas-fonds humides, Aune blanc sur les croupes sèches et dépourvues de végétation).

Dès maintenant, les instructions données par l'Administration forestière sont précises: tout défrichement de mauvais bois doit être compensé par la plantation, à l'aide d'essences précieuses, d'un terrain de surface plus restreinte, mais de forme et de situation très judicieusement choisies.

\section{CONCLUSION}

\section{Le nouvel équilibre agro-sylvo-pastoral en Champagne.}

$\mathrm{Si}$ on résume les principales idées que nous avons exposées cidessus, on constate que, peu à peu, un nouvel équilibre, différent de l'équilibre primitif, tend à se constituer: les mises en valeur intensives remplaçant, en effet, progressivement les anciennes méthodes extensives. Nous conclurons en passant en revue la place respective que doivent tenir les 3 modes de mise en valeur: culture - élevage forêt - dans ce nouvel équilibre.

\section{a) La culture.}

Nous avons dit qu'il s'agissait essentiellement de cultures intensives, produisant de gros rendements, le sol n'étant plus considéré que comme un support. Mais quelles sont les cultures qui doivent être introduites dans l'assolement? Pour répondre à cette question, 
il est nécessaire de tenir compte, d'une part, de la conjoncture économique, d'autre part, du maintien de la fertilité du sol, dont il a déjà été question.

- Au point de vue économique, il faut reconnaitre que la production massive de betterave à sucre, à laquelle se sont livrées les premières grandes exploitations, semble avoir été une erreur, étant donné la crise qui sévit actuellement sur le sucre et l'alcool, en pleine surproduction. Il est donc nécessaire de freiner cette tendance et de remplacer la betterave à sucre par une autre culture sarclée, comme tête d'assolement: à cet effet, la betterave fourragère (betterave danoise) parait être tout indiquée: elle permettra l'extension de l'élevage et elle offre également l'avantage d'améliorer le taux d'humus, grâce aux nombreux déchets qu'elle laisse et qui peuvent être incorporés au sol.

Les céréales, par contre - surtout le blé, l'orge de brasserie continueront à jouer leur rôle de premier plan, comme dans l'assolement actuel.

- Au point de vue du sol, rappelons que le cultivateur ne devra jamais perdre de vue le maintien d'un taux d'humus suffisant: l'intercalation dans l'assolement de cultures de prairies artificielles ou temporaires, à base de Légumineuses, est, nous l'az'ons dit, indispensable à la conservation d'une bonne structure du sol agricole.

\section{b) L'élevage.}

L'élevage doit être à nouveau mis en honneur en Champagne: mais il ne s'agira plus de l'élevage extensif d'ovins sur de maigres terrains de parcours, mais de l'élevage intensif de bovins; son développement sera lié à celui des deux cultures principales, qui constitueront - en dehors des céréales - la base de l'assolement type nouveau: la betterave fourragère et les prairies artificielles ou temporaires; ce seront là les deux sources essentielles de l'alimentation du bétail.

Mais les troupeaux rendront à l'agriculture ce qu'ils auront reçu d'elle, sous forme de fumier de qualité, qui, nous l'avons dit, doit être incorporé à hautes doses dans les sols de craie, si l'on ne veut pas voir sa valeur de support physique diminuer dangereusement et les rendements décroitre rapidement:

Agriculture et Elevage apparaissent donc comme étroitement liés et complémentaires l'un de l'autre.

c) La forêt.

A la forêt sera dévolue une place nettement plus restreinte qu'à la culture et à l'élevage, car le sol champenois, reconnaissons-le, n'est pas, malgré sa pauvreté naturelle, un sol à vocation forestiè- 
re. Mais le maintien d'une surface boisée de l'ordre de 5 à ro \% est indispensable à l'équilibre physique, sinon économique du pays; elle fournira des produits rentables( bois de mine et papeterie), grâce à la substitution au Pin sylvestre d'essences plus intéressantes. Nous n'insisterons pas sur le rôle social de la forêt qui fournira un travail d'hiver aux ouvriers agricoles.

Ainsi, une fois de plus, la nécessité d'un équilibre, entre les différentes formes de mise en valeur, s'imposera pour la Champagne comme pour les autres régions de France. Cet équilibre est nécessaire à tous les points de vue: physique, économique, social. C'est pour avoir parfois méconnu cette grande loi que l'homme a provoqué de véritables catastrophes: C'est ainsi, par exemple, que l'érosion éolienne a dévasté le sol des plaines centrales des U.S.A., livrées d'une manière trop exclusive à la culture de céréales; et que l'incendie a ravagé la forêt landaise, dont le manteau uniforme couvrait près d'un million d'hectares!

Ph. Duchaufour. 


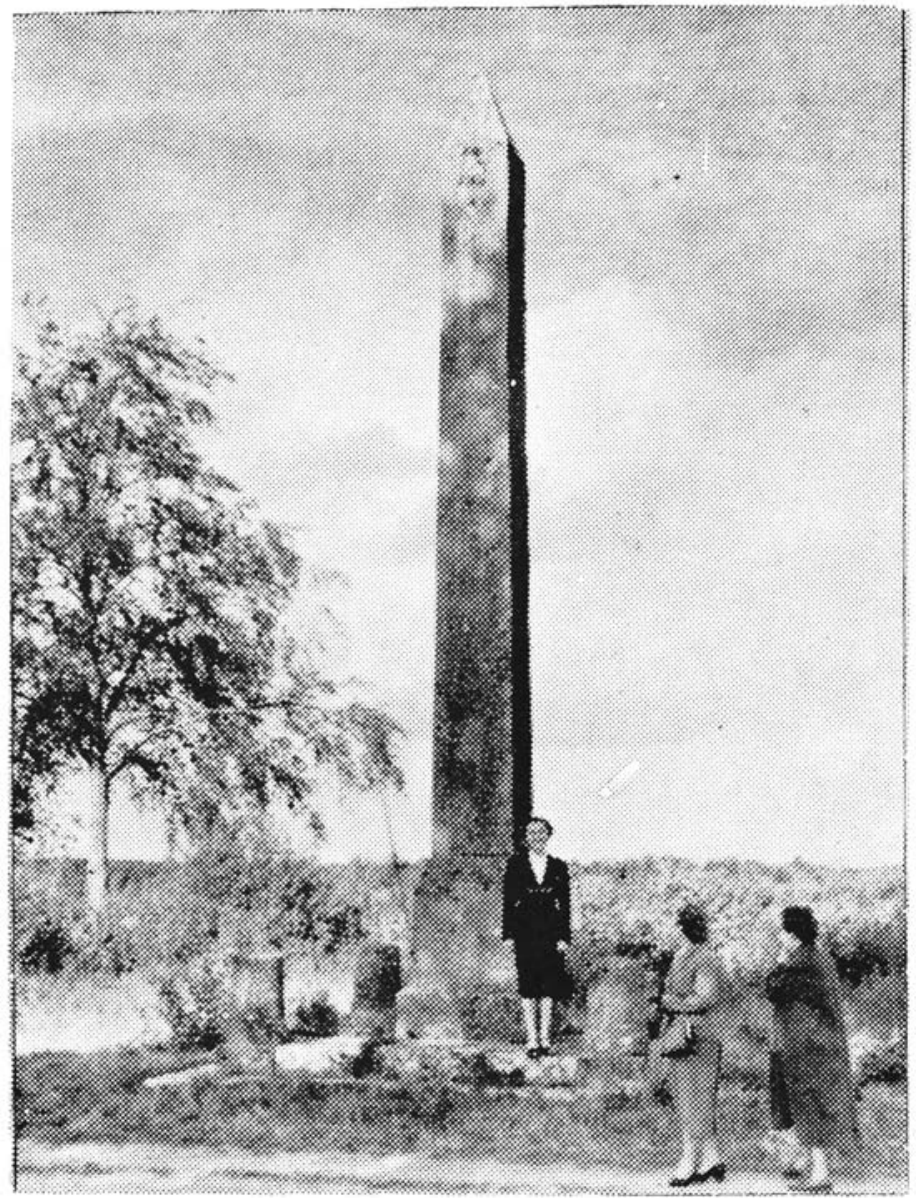

LABÉLASQUE DE VALDÉPART

Entre Villeloup et Echemines

On y lit sur une face:

«En I8 6 , Baltet-Petit planta les premiers sapins

dans les friches de ces contrées 》

Lin rédacteur de l'Est-Eclair propose de 15 octobre 1953 d'ajouter:

«C'est en 1950 que M. Quak

a arraché les pins pour livrer à̀ nouveau

ces terres fécondées à la culture »

Mais la Nature a-t-elle été consultée?

(Cliché aimablement prêté par l'Est-Eclair.) 